\title{
Direct Processing of Structural Thermoplastic Composites Using Rapid Isothermal Stamp Forming
}

\author{
N. Reynolds ${ }^{1}$ (D) - S. Awang-Ngah ${ }^{1} \cdot$ G. Williams ${ }^{1} \cdot$ D. J. Hughes ${ }^{1}$
}

Received: 20 September 2019 / Revised: 4 March 2020 / Accepted: 9 March 2020

Published online: 7 April 2020

(C) The Author(s) 2020

\begin{abstract}
A novel rapid isothermal stamp forming process is proposed which enables the rapid manufacture of structural thermoplastic composite laminate parts directly from multilayer hybrid fabrics comprising stitched unidirectional carbon fibre-thermoplastic polymer veil. The process employs rapid-response variothermal tooling, allowing macro-scale (fabric forming/draping) and micro-scale (fibre wetting/laminate consolidation) composite material transformation processes to occur isothermally above the constituent polymer matrix melt temperature $\left(\mathrm{T}_{\mathrm{m}}\right)$, thus manufacturing a composite component directly from a hybrid dry fabric in a single press cycle in a relatively short overall cycle time. The proposed rapid isothermal stamp forming (RISF) concept is presented, and details of the process are given along with some considerations made throughout the formulation of the process. As a result of the RISF process development work, candidate manufacturing parameters were derived, delivering parts that exhibit acceptable composite laminate microstructure and mechanical performance within a press station cycle time of $330 \mathrm{~s}$.
\end{abstract}

Keywords A: Carbon fibres, thermoplastic resin · D: Process monitoring · E: Stamp forming

\section{Introduction}

Engineering polymer-based thermoplastic composites (eTPCs) are competitive from a materials cost and performance standpoint [1], can be used in rapid manufacturing processes [2] and possess inherent reusability/recyclability [3]. Despite numerous research and industrial demonstrator studies on the use of rapid non-isothermal stamp-forming process for TPC laminates (including commodity polymer-based TPCs) [4-10], high-volume industrial applications are scarce, with such applications for these materials being limited to their inclusion as discrete performance-enhancing inserts within highly-integrated injection moulded

N. Reynolds

neil.reynolds@warwick.ac.uk

1 WMG, University of Warwick, Coventry CV4 7AL, UK 
components $[11,12]$. In many cases, the eTPC laminate enters the process as a pre-wetted/ partially consolidated semi-finished sheet material from which blanks are cut, preheated and processed. Therefore the moulding process is transforming the material on a macro-scale in a relatively low-pressure thermoforming/shaping step. Prior to stamping, impregnation and consolidation has already occurred in the semi-finishing stage and the only microstructural improvement to occur is the collapsing of voids that have arisen during blank preheating due to fibre-bed relaxation [13]. Moreover, pre-wetting and consolidation steps are often performed before rapid stamp-forming as there are inherent limitations on what microstructural transformations can be achieved during the short time at which the matrix material is at moulding pressure and in melt phase due to the quenching that occurs in a rapid non-isothermal process [14]. However, any pre-impregnation (pre-pregging) processing step in creating the wetted/ consolidated semi-finished material inevitably adds cost to the material as supplied.

Static (isothermal) pressing is employed for low-volume production/high-performance applications and typically delivers high part quality through controlled microstructural and polymer morphology manipulation [15]. Typically the entire press platens and tooling contained therein are heated to temperatures above the melt temperature of the selected polymer matrix and then the part and tooling are held for a dwell period at the prescribed press tonnage and temperature. Following the isothermal dwell, the platens, tooling and part are cooled at a predetermined rate thus controlling the resultant crystallinity of the polymer matrix in the final part. This control of microstructure and polymer morphology is critical when processing costly performance polymers for demanding applications (e.g. aerospace). This paper presents for the first time a new methodolgy to enable the rapid manufacture of structural thermoplastic composite laminate parts directly from multilayer hybrid fabrics comprising stitched unidirectional carbon fibre-thermoplastic polymer veil fabrics. The process is facilitated by the use of advanced vario-thermal tooling resulting in press cycle times of $330 \mathrm{~s}$.

\subsection{Rapid Isothermal Stamp Forming Concept}

In this paper a rapid isothermal stamp forming (RISF) process is proposed which combines aspects of rapid (non-isothermal) and static (isothermal) press forming processes to yield a manufacturing route that enables the direct manufacture of structural TPC laminate components from hybrid carbon fibre-engineering polymer multilayer fabrics: materials that are typically difficult to process at scale due to the inherently long through-thickness flow lengths [14]. The essence of the concept is to use thermally-agile variothermal tooling to isothermally melt process the hybrid multilayer eTPC material in terms of simultaneous wetting-out, laminate consolidation and component forming before rapidly quenching the material to enable demoulding to occur within a time frame that supports medium volume industrial manufacturing (Fig. 1).

\section{Materials and Methodology}

The material employed in this study was a 4-layer hybrid non-crimp fabric (NCF) comprising two 125 gsm layers of aligned, continuous unidirectional 12K carbon fibre tows interleaved with thermoplastic non-woven $73 \mathrm{gsm}$ veil made from polyamide 66 (PA66) filaments, all layers stitch-bonded with a polyester yarn in the through-thickness direction. The biaxial UD cf. layers are orientated in $\pm 45^{\circ}$ with respect to the roll direction. A progressive (throughthickness) partial cutaway of the material as-supplied is shown in Fig. 2. This 4-layer hybrid 


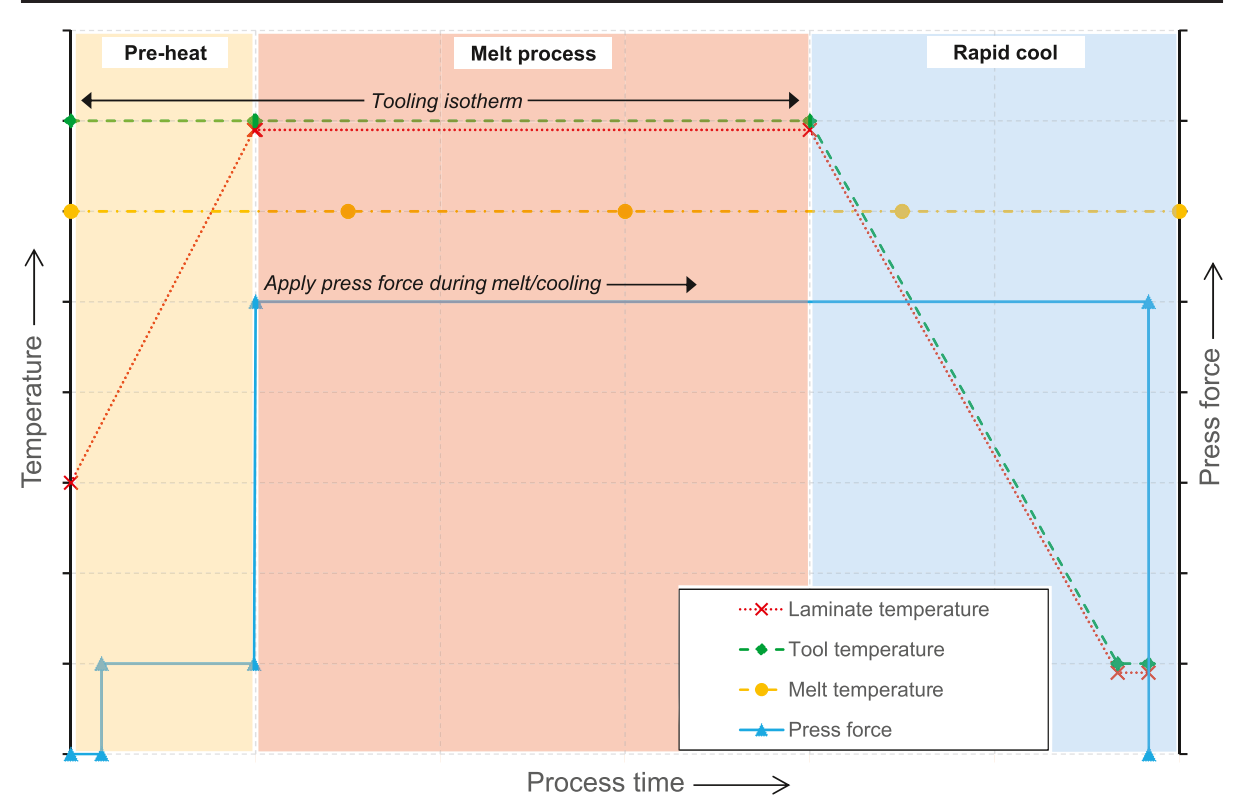

Fig. 1 RISF process schematic

NCF enables the production of an approximately 50:50 fibre-matrix volume fraction material, assuming nil void fraction following processing. The UD cf. tow is designated T700SC 60E, produced by Toray Carbon Fiber America, Inc. and the lightweight nonwoven PA66 veil was produced and supplied by Technical Fibre Products, UK. The assembly and stitching of the multilayer hybrid NCF was carried out by Sigmatex, UK.

The variothermal tooling control system was designed and manufactured by Surface Generation Ltd and is based on their production to functional specification (PtFS) technology [16]. The controller system uses compressed air and $600 \mathrm{~W}$ cartridge heaters to independently heat and cool an array of 16 separate channels on both thin-wall steel tooling faces. Using this 32 channel system with Surface Generation's proprietary control software, multi-stage heating/ isotherm/cooling profiles can be designed and executed using a variety of control strategies.

The tooling faces were manufactured from P20 steel using the authors' generic component design and from a tooling concept created by the authors. The component was based on an extruded generic 2D U-profile design of $2 \mathrm{~mm}$ wall thickness with the addition of doublecurvature ends to study fabric formability through drape, thus creating an enclosed 'bathtub' geometry. The trimmed component was $515 \mathrm{~mm}$ long and $131 \mathrm{~mm}$ wide.

The lower cavity tool features a $2 \mathrm{~mm}$ thin-wall tooling surface and the upper core tool features a $3 \mathrm{~mm}$ thin-wall tooling surface. The thin-wall tooling surfaces are supported by a verticallyoriented rear support structure that also divides the rear of each tool into 16 discrete equal-sized square heating zones into which the heated/cooled compressed air for each control channel is directed. Additionally, the tool incorporates a pinch-off edge condition corresponding to the component trim line, locally reducing the cavity offset to $1 \mathrm{~mm}$ to minimise polymer matrix egress during melt impregnation and consolidation. A cross-section drawing of the thin-wall tooling with support structure is shown in Fig. 3a and b shows the tool system loaded in the press facility.

This particular combination of tool face design and $20 \mathrm{~kW}$ heater system can achieve 90 ${ }^{\circ} \mathrm{C} / \mathrm{min}$ heating rates (at the tool surfaces) and $60^{\circ} \mathrm{C} / \mathrm{min}$ cooling rates. The tooling system was 


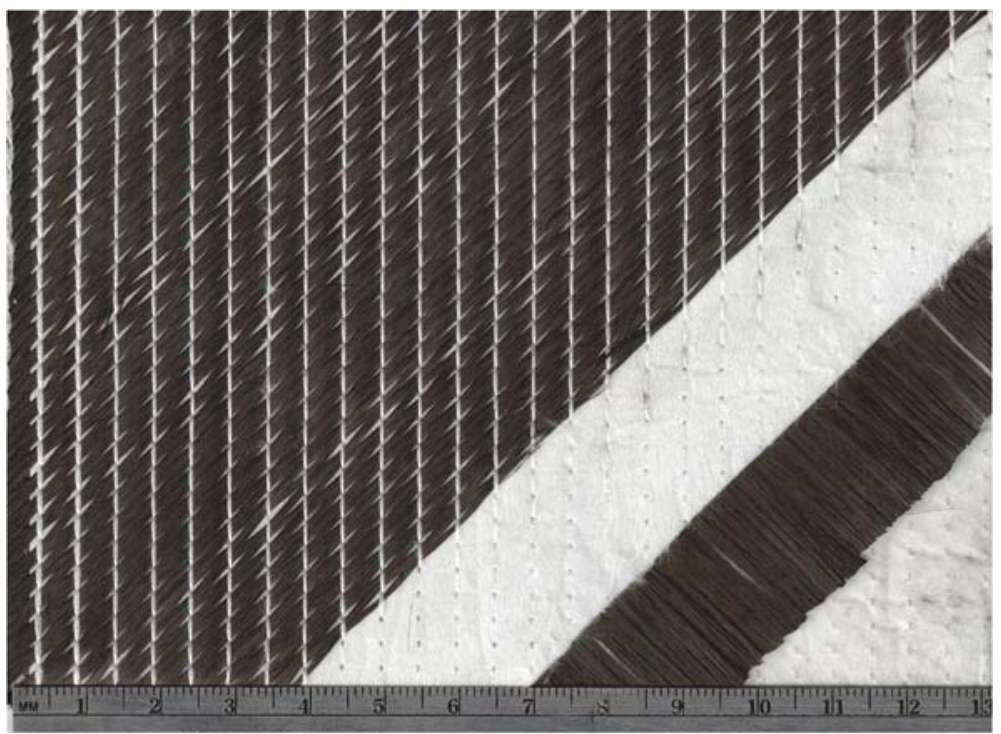

Fig. 2 Scan of partial cutaway of 4-layer hybrid non-crimp fabric (NCF), as supplied

used in a $950 \mathrm{kN}$ capacity press. The press was retrofitted with instrumentation enabling the collection of process data: estimated applied clamping force, vertical platen position, temperature at mid-plane within the laminate. Fabric preheating at below $\mathrm{T}_{\mathrm{m}}$ was carried out via contact heating within an Elkom Mikutherm-Optimal contact heating station [17].

Prior to the manufacturing study, thermal analysis was carried out on 'as received' hybrid NCF CF/PA66 to understand the material behaviour under temperature influence and to establish the outline temperature range for the forming process. Particularly, a Mettler Toledo DSC1 was used to measure the melting and crystallisation point of the material. Circa $3 \mathrm{mg}$ of the veil was isolated and weighed in an aluminium crucible and were heated from 30 to $285^{\circ} \mathrm{C}$ and cooled back to ambient temperature under nitrgoen atmosphere. Constant heating and cooling rate of $10{ }^{\circ} \mathrm{C} / \mathrm{min}$ were applied. The $\mathrm{T}_{\mathrm{g}}$ of the

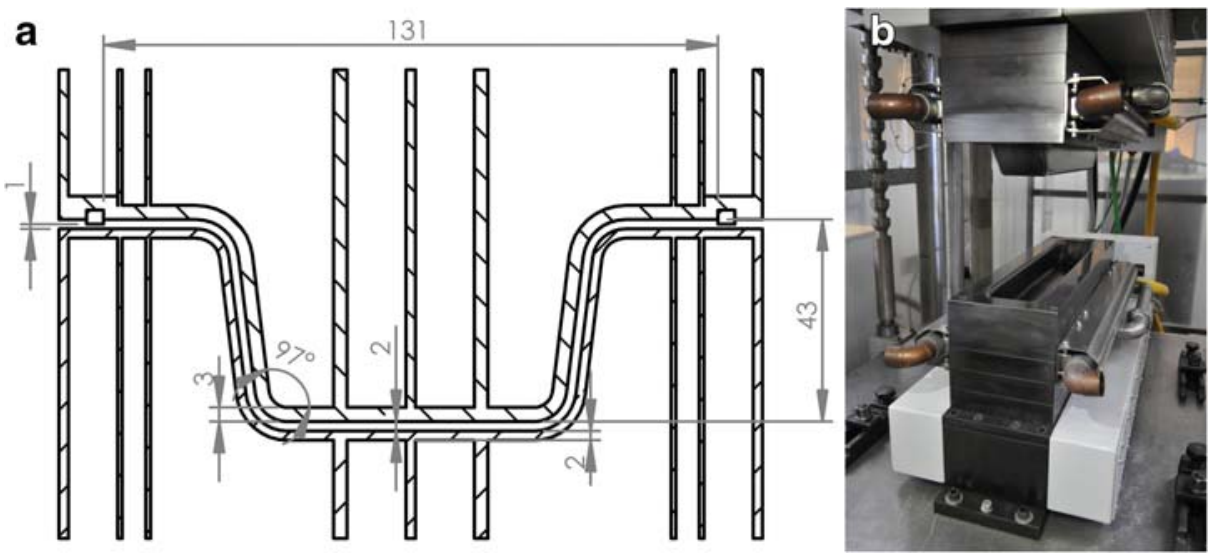

Fig. 3 Variothermal tooling: a transverse cross section, dimensions in $\mathrm{mm}$; b located in $950 \mathrm{kN}$ laboratory press 
PA66 material was not measured (either in as-supplied state or following processing), but is reported as $\sim 47{ }^{\circ} \mathrm{C}[18]$.

The 4-step RISF process is described below. Experimentally-obtained process data from a $330 \mathrm{~s}$ press moulding cycle is shown later in Fig. 5.

- Step 1: Fabric preheat (180 s), $T<T_{m}$.

- Contact heating station at $245^{\circ} \mathrm{C}$, enables 'warm' forming of dry hybrid fabric, with softened stiching and matrix veil.

- Step 2: Fabric draping (30 s), $T<=T_{m}$.

- Transfer 'warm' dry hybrid fabric to hot tool (Tool at $285^{\circ} \mathrm{C},>\mathrm{T}_{\mathrm{m}}$ ).

- Drape/pre-form using reduced clamping force.

- Step 3: Isothermal melt processing (120-210 s), $T>>T_{m}$.

- PA66 veil fully molten, $\mathrm{T}=>285^{\circ} \mathrm{C}$ : matrix phase available for wetting.

- Apply full clamping force (optional: pulsed clamping force): fibre bundle impregnation.

- Isothermal dwell: laminate consolidation and final forming.

- Step 4: Part cooling (90 s), $T<<T_{m}$.

- Rapid cooling of tooling surfaces down to $\mathrm{T}<<\mathrm{T}_{\mathrm{m}}$.

- De-mould part.

Note that during the above process, the polyester (PET) stitching yarn will be softened at drape stage (Step 1 - Step 2) and molten throughout isothermal melt processing (step 3); this is expected to significantly aid formability by allowing inter-ply rotation required for in-plane shear deformations.

Throughout the development of the RISF process, voids were commonly observed: large inter-tow voids due to limited flow around the fibre bundles and smaller-scale intra-tow as a result of incomplete wetting toward the centres of the tows during melt impregnation. The structure of the multilayer hybrid fabric is such that the matrix veil is discrete to the cf. tows and this increases the distance that the matrix must percolate through the fibre tows to achieve full wetting; in order to address this, it was hypothesised that the repeated removal and reapplication of clamp force would correspondingly expand and collapse dry fibre bundles, forcing matrix into the tows and thus increase wetting levels for shorter times and pressures (following Trudel-Boucher [19]). Particularly, in [19] applied press force was modulated at 50 $\mathrm{kN} / \mathrm{s}$ during non-isothermal processing and was not found to have a positive effect (due to the rapid cooling of the matrix material), whereas the current study investigated a similar approach but performed during isothermal processing above $T_{m}$.

$\mathrm{V}_{\mathrm{vf}}$ estimates were made via digital image thresholding analyses within ImageJ [20] using digital (optical brightfield) micrographs taken at 10x magnification on a Zeiss Axiovision system with MRc5 camera.

Candidate process parameters comprising an average in-mould pressure of $4 \mathrm{MPa}$ (with additional 5 times press clamp force pulses) and an isotherm of $120 \mathrm{~s}$ at $285{ }^{\circ} \mathrm{C}$ were used to manufacture beams from hybrid fabric with the principal fibre direction aligned parallel to the beam axis, making $0^{\circ} / 90^{\circ}$ balanced ('crossply') laminate parts. In order to evaluate the mechanical performance of the RISF-processed PA66-CF laminate, static tensile testing in accordance with ISO527-4 was performed on specimens extracted from flat regions of the generic component [21]. These samples were extracted orientated at $0^{\circ}$ (along the beam axis), and it was possible to extract 2 test specimens each from 2 manufactured beams - i.e. at total of 4 test specimens. Type $1 \mathrm{~B}$ geometry ('dogbone' with $60 \mathrm{~mm}$ gauge region, $10 \mathrm{~mm}$ gauge 
width) was selected due to the availability of material in suitably flat regions of the component; therefore obtained mechanical performance data (particularly with regards to strength) is presented as indicative. $\mathrm{F}_{\mathrm{vf}}$ estimates were made from sections of these tested candidate beams using the same optical microscopy method as above.

\section{Results and Discussion}

The DSC analysis of the as-received PA6 veil indicated a $\mathrm{T}_{\mathrm{m}}$ of $258{ }^{\circ} \mathrm{C}$ (peak) and the crystallisation temperature for the material is around $230{ }^{\circ} \mathrm{C}$ (Fig. 4).

Figure 5 shows the process data from a typical RISF press cycle. The modulation of applied press clamping force is seen at approximately $30 \mathrm{~s}$ press cycle time. Figure 6 displays a compound micrograph demonstrating the obtained laminate microstructure from different parts processed using RISF: with and without pulsed (modulated) press clamp force.

An example result from the void volume fraction image threshold analysis is overlaid here and the quantity and nature of the voids clearly differs according to the process, with several large inter-tow voids visible in the material taken from the part moulded without force modulation. Indeed, the estimated void volume fraction within material obtained from material manufactured with modulation of press clamp force during melt processing was $\mathbf{1 . 5 2 \%}$ as compared to $\mathbf{4 . 6 8 \%}$ within a part processed in an otherwise identical manner but without the pulsed clamping force.

The mechanical test specimens extracted from the candidate (cross-ply) RISF-manufactured three-dimensional parts yielded a mean tensile modulus of $\mathbf{6 0 . 8 4} \pm \mathbf{5 . 1 3} \mathrm{GPa}$ and a tensile strength of $\mathbf{5 3 5 . 9 5} \pm \mathbf{2 4 . 3 6} \mathbf{~ M P a}$, and this manufactured material had an estimated fibre volume fraction of $\mathbf{4 9 . 6 1 \%}$. For comparison purposes, McDonnell [22] reported a tensile modulus of 62.9 GPa and tensile strength of 788.3 MPa for a commingled (hybrid yarn) woven carbon-fibre/PA-12 composite at $\mathbf{5 8 \%} \mathrm{F}_{\mathrm{vf}}$. This reference material was (isothermally)

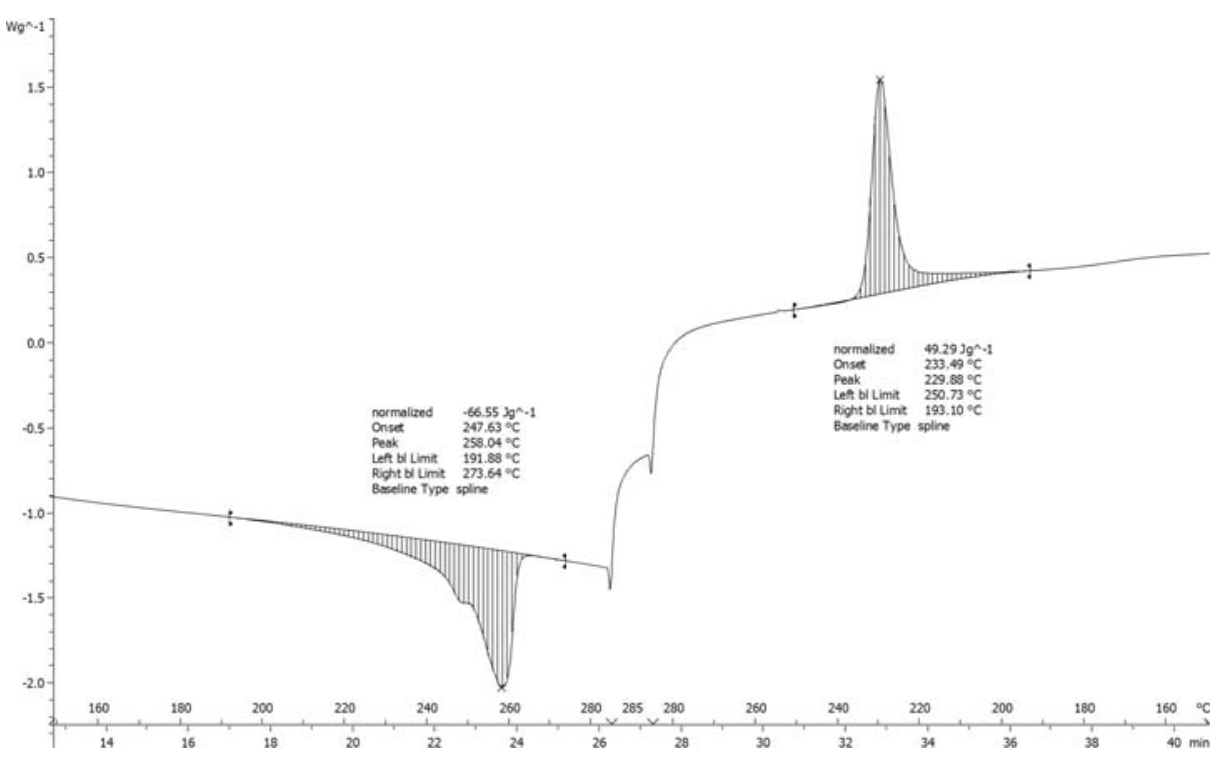

Fig. 4 DSC curve obtained from $\sim 3 \mathrm{mg}$ of PA66 veil, $10^{\circ} \mathrm{C} /$ minute heating and cooling 


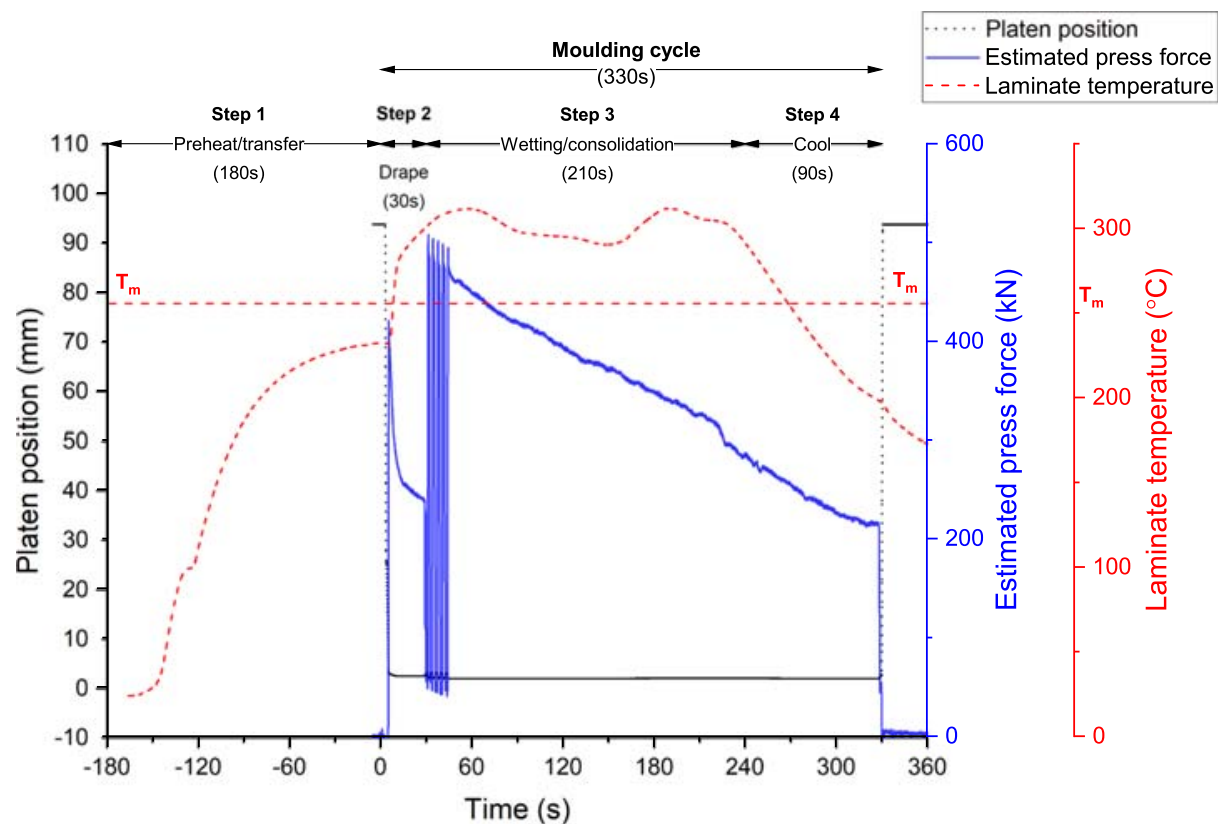

Fig. 5 Process data (platen position, press force, laminate temperature) versus time for $330 \mathrm{~s}$ moulding cycle, including $5 \mathrm{x}$ clamp force pulses at $\mathrm{t}=30 \mathrm{~s}$

static pressed, with a total cycle time of over $50 \mathrm{~min}$. The tensile modulus of the RISF material compares favourably to the referenced benchmark material - particularly considering the $\mathrm{F}_{\mathrm{vf}}$ is $16 \%$ lower. It is proposed that the lower observed strength of the RISF-manufactured material

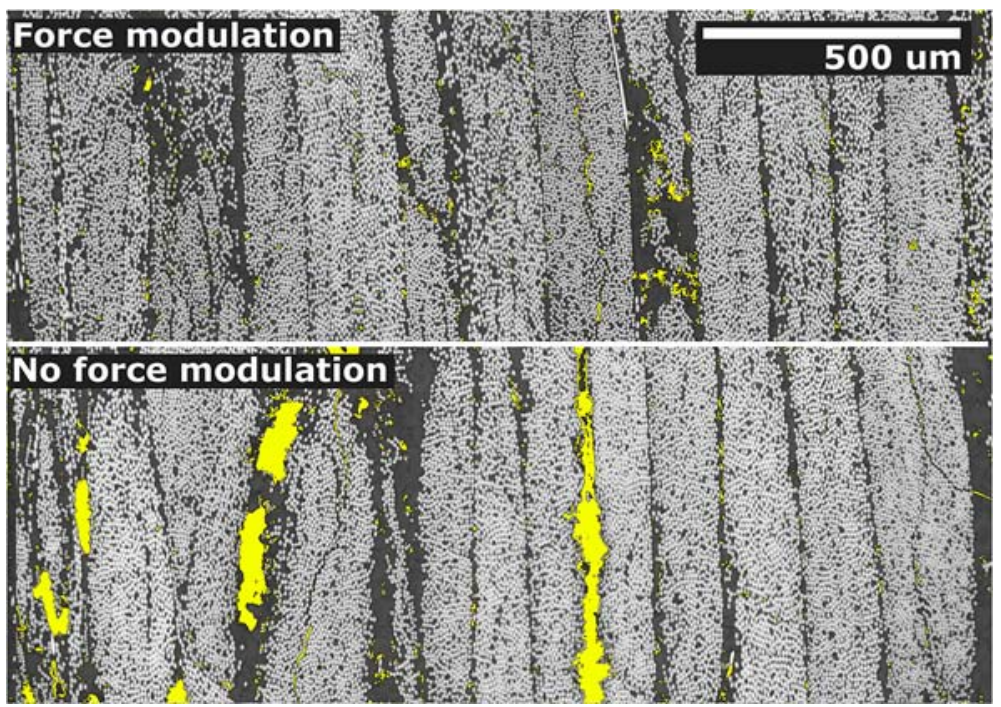

Fig. 6 Through-laminate-thickness optical micrograph of RISF-manufactured PA66-CF60 laminates, processed with and without press clamp force modulation (10x brightfield), following thresholding analyses 
arises from both the reduced $F_{v f}$ and the fact the RISF samples were extracted from a geometrically complex moulded part rather than a simple flat plate as per the referenced study, and that the forming mechanisms for the complex part [23] such as drape (in-plane shear) and matrix flow (fibre wash) will inevitably result in fibre tow misalignments and hence a strength reduction.

\section{Conclusions}

The newly-developed RISF composite laminate manufacturing process has been demonstrated as a candidate for the rapid manufacture of structural parts directly from a thermoplastic polymer-carbon fibre hybrid multilayer fabric, without the need for any preconsolidation step. Press cycle times of circa 6 min were achieved using non-optimised candidate process parameters, demonstrating suitability of the RISF process to medium-volume manufacturing; process optimisation studies are ongoing. It is concluded that the combination of particular RISF process characteristics such as isothermal melt processing and the modulation of applied press force during melt results in a viable route for the industrial processing of thermoplastic composite hybrid fabrics.

Acknowledgements This work was supported by the UK AMSCI Composites Innovation Cluster (CiC) Thermocomp project. The authors would like to acknowledge the support of the Thermocomp project partners.

Open Access This article is licensed under a Creative Commons Attribution 4.0 International License, which permits use, sharing, adaptation, distribution and reproduction in any medium or format, as long as you give appropriate credit to the original author(s) and the source, provide a link to the Creative Commons licence, and indicate if changes were made. The images or other third party material in this article are included in the article's Creative Commons licence, unless indicated otherwise in a credit line to the material. If material is not included in the article's Creative Commons licence and your intended use is not permitted by statutory regulation or exceeds the permitted use, you will need to obtain permission directly from the copyright holder. To view a copy of this licence, visit http://creativecommons.org/licenses/by/4.0/.

\section{References}

1. Krause, W., Henning, F., Tröster, S., Geiger, O., Eyerer, P.: LFT-D — a process technology for large scale production of fiber reinforced thermoplastic components. J. Thermoplast. Compos. Mater. 16(4), 289-302 (2003)

2. Rypkema, A.: QSP: A Breakthrough Approach for Automating High Performance Thermoplastic Composites. Automotive Composites Conference \& Exhibition 2015 (ACCE 2015): Society of Plastics Engineers (SPE); 2015

3. Bernasconi, A., Davoli, P., Armanni, C.: Fatigue strength of a clutch pedal made of reprocessed short glass fibre reinforced polyamide. Int. J. Fatigue 32(1), 100-107 (2010)

4. Joppich, T., Doerr, D., Meulen Lvd, Link, T., Hangs, B., Henning, F.: Layup and process dependent wrinkling behavior of PPS/CF UD tape-laminates during non-isothermal press forming into a complex component. AIP Conf Proc. 1769(1):170012 (2016)

5. Emerson, D., Grauer, D., Hangs, B., Reif, M., Henning, F., Martsman, A., et al.: Using Unidirectional Glass Tapes to Improve Impact Performance of Thermoplastic Composites in Automotive Applications. 12th Automotive Composites Conference Exhibition: SPE; 2012

6. Wakeman, M.D., Zingraff, L., Bourban, P.E., Månson, J.A.E., Blanchard, P.: Stamp forming of carbon fibre/ PA12 composites - a comparison of a reactive impregnation process and a commingled yarn system. Compos. Sci. Technol. 66(1):19-35 (2006) 
7. Wakeman, M.D., Cain, T.A., Rudd, C.D., Brooks, R., Long, A.C.: Compression moulding of glass and polypropylene composites for optimised macro- and micro- mechanical properties - 1 commingled glass and polypropylene. Compos. Sci. Technol. 58(12):1879-1898 (1998)

8. Wakeman MD, Cain TA, Rudd CD, Brooks R, Long AC (1999) Compression moulding of glass and polypropylene composites for optimised macro- and micro- mechanical properties 3 . Sandwich structures of GMTS and commingled fabrics. Compos. Sci. Technol. 59(8):1153-1167

9. Wakeman, M.D., Blanchard, P., Manson, J.-A.E.: Void Evolution During Stamp-Forming of Thermoplastic Composites. Durban, South Africa: 15th International Conference on Composite Materials; 2005

10. Jansson, N., Wakeman, W.D., Månson, J.A.E.: Optimization of hybrid thermoplastic composite structures using surrogate models and genetic algorithms. Compos. Struct. 80(1), 21-31 (2007)

11. Stewart, R.: Rebounding automotive industry welcome news for FRP. Reinf. Plast. 55(1), 38-44 (2011)

12. Nichols, C.: Advancing Structural Capability of Injection Molded Components with Continuous Fiber Reinforcement - Seat Pan Opel Astra OPC. Automotive Composites Conference \& Exhibition 2013 (ACCE 2013): Society of Plastics Engineers (SPE); 2013

13. Slange, T.K., Warnet, L., Grouve, W.J.B., Akkerman, R.: Influence of preconsolidation on consolidation quality after stamp forming of C/PEEK composites. AIP Conf. Proc. 1769(1):170022 (2016)

14. Schneeberger, C., Wong, J.C.H., Ermanni, P.: Hybrid bicomponent fibres for thermoplastic composite preforms. Compos. Part A: Appl. Sci. Manufac. 103, 69-73 (2017)

15. Brooks, R.: Forming technology for thermoplastic composites. In: Long, A.C. (ed.) Composites forming technologies: Woodhead Publishing Limited; 2007. pp. 256-276

16. Surface Generation Ltd - web site. 2018. p. Surface Generation Ltd - About

17. ELKOM-Elektroheizplatten-Technik GmbH. 2018. p. ELKOM-Elektroheizplatten-Technik GmbH - About us

18. Lu, H., Xu, X., Li, X., Zhang, Z.: Morphology, crystallization and dynamic mechanical properties of PA66/ nano-SiO2 composites. Bull. Mater. Sci. 29(5), 485-490 (2006)

19. Trudel-Boucher, D., Fisa, B., Denault, J., Gagnon, P.: Experimental investigation of stamp forming of unconsolidated commingled E-glass/polypropylene fabrics. Compos. Sci. Technol. 66:555-570 (2006)

20. Schneider, C.A., Rasband, W.S., Eliceiri, K.W.: NIH Image to ImageJ: 25 years of image analysis. Nat. Methods 9, 671 (2012)

21. BSI. BS EN ISO 527-4:1997 (BS 2782-3:Method 326F:1997), Plastics — determination of tensile properties, Part 4: test conditions for isotropic and orthotropic fibre-reinforced plastic composites. 1997

22. McDonnell, P., McGarvey, K.P., Rochford, L., Ó Brádaigh CM: Processing and mechanical properties evaluation of a commingled carbon-fibre/PA-12 composite. Compos. Part A: Appl. Sci. Manufac. 32(7), 925-932 (2001)

23. Cogswell, F.N.: The experience of thermoplastic structural composites during processing. Compos. Manuf. 2(3):208-216 (1991)

Publisher's Note Springer Nature remains neutral with regard to jurisdictional claims in published maps and institutional affiliations. 